\title{
Interaçáo Entre Crianças com Deficiência Visual em Grupos de BRINCADEIRA
}

InTERACTION Among Visually Impaired ChildRen in PLAY GRoups

\author{
Letícia Coelho RUIZ ${ }^{1}$ \\ Cecília Guarnieri BATISTA²
}

\begin{abstract}
RESUMO: os estudos sobre o brincar e o desenvolvimento de crianças com deficiência visual tem destacado os obstáculos que podem surgir na interação com parceiros. No presente estudo, buscou-se analisar as formas de interação entre as crianças e de atuaçáo do adulto, em situação de brincadeira faz de conta, identificando possíveis dificuldades e soluçôes para as mesmas. Foram observadas duas crianças de cinco anos, com deficiência visual (cegueira e baixa visão) e dificuldades escolares. As sessōes foram filmadas e foram selecionados episódios de interação entre os participantes, com foco nas capacidades e dificuldades no contexto grupal. A análise foi baseada em categorias referentes à intervenção do adulto pesquisador e à interação entre crianças nas brincadeiras infantis. A análise dos dados indicou exemplos de habilidades e iniciativas das crianças na elaboração de cenas e enredos, bem como algumas dificuldades na interação entre elas. Destacou a atuação da pesquisadora na promoção da brincadeira, a partir de necessidades identificadas a cada momento da interaçáo, como, por exemplo, a descrição de açóes e objetos para a criança cega e a intervenção em caso de disputas. Considerou-se que grupos de brincadeira favorecem a interação entre crianças com deficiência visual e destacou-se o papel do adulto nesse contexto. Esses aspectos foram considerados relevantes para o planejamento pedagógico no contexto da educação inclusiva.
\end{abstract}

PALAVRAS-CHAVES: Educação Especial. Deficiências da visão. Brinquedo. Interação social. Psicologia do Desenvolvimento.

ABSTRACT: Studies about play and development of children with visual impairments have emphasized different obstacles than emerge during interaction with their playmates. In the present study, modes of child-child interaction and of adult intervention in make-believe group play were analyzed. Possible challenges and solutions for child participation were identified. The participants were two visually impaired children (blindness and low vision) aged five years who presented school difficulties. The sessions were filmed and episodes of interaction among participants were selected, focusing on capacities and difficulties in the group context. The analysis was based on categories related to the intervention of the adult researcher and to child-child interaction during play. The analysis indicated instances of abilities and initiatives of the children in elaborating scenes and plots, as well as some difficulties in their interaction. The researcher's role in promoting play was also underscored in each interaction instance (e.g.: the description of actions and objects for the blind child and intervention in case of disputes). The results suggested that play groups promote interaction between visually impaired children while highlighting the role of the adult in this context. Those aspects were considered relevant for pedagogical planning in the context of inclusive education.

KEYWORDS: Special Education. Visual Impairment. Play. Social Interaction. Developmental Psychology.

\section{INTRODUÇÁo}

Diversos estudos têm buscado discutir a importância do brinquedo e da brincadeira para o desenvolvimento de crianças que apresentam alguma deficiência. Bomtempo (2000) destaca que, para se conhecer bem uma criança, deve-se conhecer seus brinquedos e suas formas de brincar. Esta abordagem vem da compreensão sobre a relação entre brincar e o desenvolvimento infantil. Huizinga (2008) sugere que a espécie humana seja identificada como Homo Ludens, tamanha a importância e presença do jogo na vida humana. O historiador

\footnotetext{
${ }^{1}$ Pedagoga, Mestre em Saúde, Reabilitação e Interdisciplinaridade. Universidade Estadual de Campinas, Faculdade de Ciências Médicas, Campinas, SP, Brasil. letsruiz@yahoo.com.br

${ }^{2}$ Professora doutora em Psicologia, Departamento de Desenvolvimento Humano e Reabilitação, Centro de Estudos e Pesquisa em Reabilitação, Faculdade de Ciências Médicas, Universidade Estadual de Campinas, Campinas, SP, Brasil. cecigb@fcm.unicamp.br
} 
aborda contribuiçôes do jogo em todas as fases da vida, sua estreita relação com a cultura, e dá ênfase ao seu caráter livre. Kishimoto (1994) destaca o brincar e o jogo vinculados ao sonho, à imaginação, ao pensamento e ao símbolo. A autora discute uma concepção de ser humano como ser simbólico, que se constrói coletivamente e cuja capacidade de pensar está ligada à capacidade de sonhar, imaginar e jogar com a realidade. A autora vê o jogar como gênese da "metáfora" humana. "Ou, talvez, aquilo que nos torna realmente humanos" (KISHIMOTO, 1994, p. 21).

Ao abordar o brincar da criança, Vygotsky (1998) considera a brincadeira de faz de conta como atividade que satisfaz necessidades da criança, contribuiu para o desenvolvimento do pensamento e lhe permite vivenciar situaçóes da vida adulta e interpretar a realidade que a cerca. Afirma que o brinquedo cria uma zona de desenvolvimento proximal na criança, de forma que "no brinquedo a criança sempre se comporta além do comportamento habitual de sua idade, além do seu comportamento diário; no brinquedo é como se fosse maior que na realidade" (VYGOTSKY, 1998, p.134).

Situaçóes de brincadeira, e, em especial, da brincadeira faz de conta na fase da Educação Infantil, são consideradas por muitos autores como promotoras do desenvolvimento da criança. Isso é especialmente verdadeiro quando a atividade assume um caráter relativamente livre (uma vez que crianças estão sempre sob supervisão), com possibilidade de iniciativas e elaboração de diferentes modalidades de brincadeira. Entretanto, essa atividade pode ser prejudicada em crianças com deficiência, dentre as quais se destacam, no presente trabalho, as crianças com deficiência visual. Diferentes estudos buscam compreender especificidades no desenvolvimento de crianças cegas e com baixa visão, destacando, de um lado, a potencialidade desses sujeitos e, de outro, as barreiras que encontram nas relaçóes com o outro e no ambiente, que dificultam seu pleno desenvolvimento. Warren (1994) sugere que estudos sobre deficiência visual tenham como foco possíveis diferenças entre pessoas com essa deficiência, e a busca de análise de casos bem sucedidos, que podem apontar para potencialidades e para a identificação de circunstâncias que favorecem ou dificultam seu desenvolvimento.

Preisler (1997) relata um estudo longitudinal qualitativo realizado na Suécia com oito crianças com cegueira congênita, desde o nascimento até os seis anos, com um follow up aos 10 anos. Observou-se que, ao longo de todo o período pré-escolar, as crianças do estudo encontraram dificuldades na participação em atividades de brincadeira livre com crianças videntes e se limitaram a interagir com o adulto ou a brincarem sozinhas. Segundo a autora, isso aconteceu devido a pouca disponibilidade de brinquedos interessantes para as crianças cegas, já que na maioria deles predominavam pistas visuais, e ao fato de que, na brincadeira livre, era difícil para a criança cega acompanhar os movimentos das crianças videntes e perceber pistas não verbais da interação. Essas observaçóes evidenciam a necessidade de melhor compreensão dessas relaçóes, que levem a novas formas de proporcionar um ambiente mais inclusivo para estas crianças.

O estudo de Silveira, Loguercio e Sperb (2000), realizado em grupos de crianças com deficiência visual em momentos de brincadeira simbólica em contexto espontâneo e proposto, destaca que as crianças apresentaram condiçóes para se engajar em brincadeiras simbólicas nos dois contextos e apresentaram mais situaçóes de brincar simbólico no contexto proposto 
pelo adulto. Consideraram que é importante o estímulo às brincadeiras e, mesmo, ensinar as crianças com deficiência visual a brincar.

Em situaçóes de brincadeira faz de conta, é importante pensar na maneira como a criança cega pode participar das mesmas. Hueara et al. (2006) observaram crianças com deficiência visual, algumas com outros problemas de desenvolvimento de origem orgânica, em pequenos grupos, em que foram encorajadas a brincadeiras de faz de conta. As autoras constataram várias capacidades nas crianças, relativas a reconhecimento de objetos, criação de cenas e criação de narrativas. Desse modo, sugerem que as situaçóes de brincadeira de faz de conta proporcionam o reconhecimento de habilidades que normalmente não seriam notadas em atividades cotidianas e/ou totalmente dirigidas. Consideram, também, que a interação entre parceiros e a situação de brincadeira, mediada por adultos, proporcionaram um ambiente favorável às múltiplas elaboraçóes das crianças.

Oliveira e Bomtempo (2009) em consideraçóes sobre o processo lúdico e o desenvolvimento de crianças com deficiência visual, ressaltam a importância da "automotivação lúdica”, momentos criados espontaneamente no brincar, sem a tutela diretiva do adulto. Explicam que o brincar livre favorece a reorganização dos sistemas sensoriais, na medida em que a criança se movimenta e experimenta novas situações. Nesse sentido, a motivaçáo intrínseca do brincar favorece a espontaneidade do movimento e o desenvolvimento de novas habilidades.

Em vários dos estudos revisados, o olhar para a deficiência visual muda, deixando o aspecto de defeito ou perda. Passa-se a valorizar o entendimento sobre as formas de organização do conhecimento e experiências desse indivíduo. Desse modo, o foco muda: do indivíduo e seu problema, para o indivíduo e sua relação com o ambiente, que pode propiciar o desenvolvimento de seu potencial.

Nessa direção, Vygotsky (1997) afirma que a pessoa cega recebe informações por meio dos sentidos remanescentes, e as organiza por meio da linguagem. Para o autor: "A cegueira, ao criar uma configuração da personalidade nova e peculiar, dá origem a novas forças, modifica as direçôes normais das funçóes, reestrutura e forma a psique do homem de modo criativo e orgânico". (VYGOTSKY, 1997, p. 9933). Segundo sua concepção, a cegueira não deve ser considerada somente um problema, mas também uma fonte de manifestação das capacidades. Considerando a cegueira sob este ponto de vista, é importante entender os processos de reorganização do indivíduo que apresenta esta deficiência e como o ambiente em que está inserido pode interferir nesse processo.

Ao abordar a relação da pessoa com deficiência visual com sua forma particular de aprender, Masini (2007) considera que as questóes que dizem respeito às percepçóes dos sujeitos com deficiência sensorial têm sido retomadas, com foco na complexidade dos processos de construção da autopercepção e da construção do mundo ao seu redor. Assim, oferecer condiçóes para o desenvolvimento e educação de uma pessoa com deficiência sensorial requer que se entre em contato com seu viver, em diferentes momentos e situaçóes.

A partir dos estudos revisados, pode-se afirmar que as possibilidades de desenvolvimento da pessoa com deficiência visual dependem do entendimento sobre como ela

${ }^{3}$ Tradução do texto original em Espanhol 
aprende e de como é concebida em relação a seu valor social. Seu desenvolvimento depende, em grande parte, das experiências sociais com parceiros, mediadas por adultos. Ao longo dessas interaçóes, quanto mais a criança puder construir uma imagem positiva de si mesmo, com foco em suas capacidades, mais terá possibilidades de desenvolvimento e engajamento social. Nesse sentido, é importante analisar as formas como a criança com deficiência visual se relaciona com parceiros e que mecanismos facilitam seu engajamento nos grupos e sua participação ativa.

Em relação ao papel do adulto nesse processo, Nunes e Lomônaco (2010) também retomam a ideia de que as relaçóes com a pessoa cega não devem estar centradas nos limites e déficits. Afirmam ser importante que o adulto procure entender as limitaçóes da ausência de visão e analise as condiçóes de vida na família, escola e em outros grupos de referência, para buscar facilitar o desenvolvimento desse indivíduo. Para os autores, quando o adulto compreende as formas como a criança com deficiência visual aprende, pode orientá-la de forma mais específica e de acordo com as necessidades dessa criança.

Quando se compreende a importância das relaçóes e das experiências em situaçóes de convívio social, é possível favorecer esses momentos e permitir que a criança tenha mais contato com ambientes sociais diversificados. Nesse sentido é importante que as relaçóes no grupo possibilitem situações que evidenciem as potencialidades dessas crianças. Batista e Laplane (2007), ao discutirem modalidades de atendimento em grupo para crianças com deficiência visual, abordam questóes relacionadas ao "isolamento social". Discutem as dificuldades que a criança com deficiência visual tem em experimentar lugares e papéis sociais valorizados, citando como exemplo o papel da liderança. Relatam experiências documentadas nos grupos de atendimento e, a partir da análise sistemática dos dados das sessóes, apresentam exemplos de situaçóes em que os participantes se revezam para auxiliar uns aos outros, e em que vivenciam papéis de liderança e sucesso.

A partir dessas consideraçóes, observa-se que é nas relações com o meio social que a pessoa com deficiência visual vai construir uma imagem de possibilidades ou dificuldades em sua estruturação como ser social. As açóes de inclusão, nesse sentido, devem ser baseadas em estudos que busquem compreender a forma como essa pessoa se constitui, como se relaciona e percebe o mundo em que vive. Dessa forma, pode-se otimizar a orientação dos grupos de que ela participa (família, escola, comunidade), visando facilitar seu desenvolvimento

Essa preocupação foi adotada no presente estudo, que descreve e analisa as formas de brincar entre as crianças com deficiência visual, assim como a atuação do adulto neste contexto.

\section{Método}

O estudo foi realizado em um Centro de Apoio Educacional para crianças com dificuldade de aprendizagem de um município de porte médio do estado de São Paulo. O projeto foi aprovado pelo Comitê de Ética em Pesquisa da FCM-UNICAMP (parecer no 1126/2009) e os pais assinaram o Termo de Consentimento Livre e Esclarecido. As crianças participantes foram referidas por nome fictício nos relatos. 


\subsection{Participantes}

O estudo completo abrangeu dois grupos de crianças, com um total de sete participantes. Para o presente relato, foram selecionadas duas crianças do Grupo 1, com diagnóstico de deficiência visual e queixas relativas a dificuldades de aprendizagem, descritas a seguir.

Guilherme, cinco anos e seis meses. De acordo com relatório médico, apresentava cegueira, devido à retinopatia da prematuridade por descolamento de retina e nascimento prematuro (sete meses). Tinha percepção de luz e de alguns vultos. Nas observaçóes em atendimento no serviço, reconhecia as letras do primeiro nome em Braille e montava seu nome com letras móveis Braille. Manuseava tipos variados de brinquedos (jogos de encaixe, miniaturas de animais, carros, instrumentos musicais, bolas, massa de modelar, entre outros), principalmente os que emitiam algum som. Em alguns atendimentos realizava as atividades, criando personagens e fazendo de conta que era outra pessoa (amigos, professores, etc.). Estava matriculado no último ano da Educação Infantil. A professora relatou que sentia dificuldades em prover materiais adaptados para $\mathrm{G}$, devido ao pouco conhecimento sobre recursos, e porque ele reclamava quando repetiam muito o mesmo material ou quando não recebia tarefas, como os colegas. No parque costumava brincar com a monitora, sozinho ou com uma amiga da sala. Vivia com a mãe, o irmão gêmeo, avó materna, tia materna e primo. A mãe relatou que buscou orientaçóes desde o nascimento, tais como, terapias de estimulação precoce e fisioterapia, em decorrência de uma dificuldade motora apresentada, na lateral esquerda do corpo de G. Mostrou preocupação nos momentos em que o irmão não deixava $G$ fazer algumas ações, afirmando que não podia por ser cego.

Carlos, cinco anos e 10 meses. Constava em relatório médico o diagnóstico de baixa visão e quadro de microcefalia ${ }^{4}$. Nas descriçôes diagnósticas relatava-se palidez nas papilas e alteraçóes no desenvolvimento global. Segundo observações em atendimento no serviço, dispersava-se com frequência numa conversa ou atividade escolar, fazendo perguntas fora do contexto. Mostrava-se agressivo em algumas situaçóes, esquivando-se de contato físico e do envolvimento com o grupo, procurando brincadeiras individuais. Escrevia o primeiro nome em letras grandes e seus desenhos eram garatujas (sem formas definidas). Estava matriculado no último ano da Educação Infantil, período em que a escola solicitou um acompanhante escolar para auxiliá-lo nas atividades, por apresentar muita agitação, pouca concentração e dificuldades na realização das atividades escolares. Vivia com a mãe e dois irmãos mais velhos. A mãe relatava que $\mathrm{C}$ era muito agitado, e não costumava seguir as orientaçóes e ordens dela. Segundo seu relato, "só para um pouco para assistir desenhos e jogar vídeo game". Afirmou que ele costumava ficar com os irmãos, enquanto ela trabalhava (trabalho remunerado, realizado em casa) e que se desentendiam muito.

\footnotetext{
${ }^{4}$ Microcefalia (2012): é uma doença neurológica caracterizada pelo tamanho muito pequeno da cabeça em relaçấo à idade ou ao sexo do bebê ou da criança. A microcefalia pode ser congênita, adquirida ou desenvolver-se nos primeiros anos de vida. $\mathrm{O}$ desenvolvimento das funçóes motoras e da fala pode ser afetado. A hiperatividade e o retardo mental são comuns. Podem ocorrer convulsões, fraqueza dos membros, quadriplegia e paralisia.
} 


\subsection{Procedimentos de coleta de dados}

A pesquisadora apresentou a proposta de estudo para a coordenação do serviço, que permitiu que a pesquisa fosse realizada com as crianças atendidas no local. Foram organizados dois grupos de crianças, em uma das salas da instituição.

Foram realizadas oito sessóes, por um período de três meses, ao longo de um semestre letivo, e todas foram filmadas e transcritas. A pesquisadora em atuação no grupo tinha como proposta dispor condiçóes para brincadeiras entre as crianças (o que envolveu o planejamento do espaço e a escolha dos brinquedos), e acompanhar as atividades de forma a permitir iniciativas por parte do grupo. Os brinquedos foram escolhidos de acordo com algumas características: tamanho (maior que $15 \mathrm{~cm}$ ), cores contrastantes, sonoridade, textura.

\subsection{Procedimentos de ANÁlise de dAdos}

A transcrição e análise das filmagens basearam-se na análise microgenética de caráter histórico-cultural, conforme descrito por Góes (2000). Foram selecionados episódios significativos, considerando-se como episódio uma sequência interativa ou trecho de registros em que se pode delimitar um grupo de crianças pela organização espacial ou participação em uma atividade (adaptação de CARVALHO; PEDROSA, 2002). Como os temas das brincadeiras elaboradas pelo grupo desta pesquisa tinham uma duração longa, a ponto de ter continuidade em dias subsequentes à sessão iniciada, foi necessário organizar recortes por temas das brincadeiras e dentro dos temas, selecionar episódios. As filmagens foram assistidas repetidas vezes e as cenas foram transcritas de forma a detalhar os acontecimentos do enredo elaborado. Para isso foram transcritas também algumas ações não verbalizadas pelos participantes, de modo a preservar a compreensão do enredo organizado durante as sessóes e propiciar melhor análise das interaçóes.

\section{Resultados}

A partir da análise dos episódios e dos objetivos do estudo, foram organizados sistemas de categorias, centrados nos tipos de interação e no uso de objetos. São apresentados a seguir os Sistemas de Categorias de Interação Criança-criança e Adulto-criança, foco do presente relato.

Categorias de Interação criança-criança

1. Atividade individual: atuação da criança sem relação aparente com as açóes dos parceiros.

2. Atividade dirigida ao parceiro - afinidade: comentário e/ou atuação da criança em direção ao parceiro ou ao grupo, sem configurar uma ação conjunta.

3. Atividade dirigida ao parceiro - Oposição: comentário e/ou atuação da criança que mostre oposição em relação às atividades desse(s) parceiro(s), sem configurar uma ação conjunta.

4. Atividade Conjunta: atuação das crianças com elaboração conjunta de brincadeira, que pode ser só verbal ou incluir execução.

Categorias - Interação Adulto-Criança: 
1. Comentário: pergunta, constatação, explicação, expansão relativas às açôes da criança, sem uma avaliação do que está sendo feito.

2. Avaliação positiva: comentários relativos às açóes da criança, envolvendo aprovação/elogio.

3. Desaprovação: comentários relativos às açóes da criança, envolvendo advertência sobre riscos, informação e explicação sobre erros, ou desaprovação.

4. Sugestão para uso e localização do objeto: comentários relativos às açóes da criança, com sugestão para busca, exploração/montagem de objetos, não configurando faz de conta.

5. Sugestão para faz de conta: comentários relativos às açóes da criança, com sugestão para a realização de brincadeiras de faz de conta (sem foco na integração entre crianças).

6. Sugestão para Integração: comentários relativos às açóes da criança, que indicam a intenção de integraçáo das crianças presentes no grupo na mesma brincadeira e/ou diálogo.

Para o presente relato foram escolhidos três episódios da primeira sessão. Definiuse como critério de escolha que os episódios contassem com a participação do maior número possível de crianças e que contivessem açóes categorizadas como Atividade Conjunta.

\section{ANÁLISE DE EPISÓdIOS}

\section{G1-SESSÃo - O LOBO E O PORQUINHO}

Crianças presentes: Guilherme (G), Carlos (C), Pesquisadora (P).

Brinquedos disponíveis: blocos de madeira, bonecos de pano, casa de plástico com encaixes no telhado, carros em miniatura.

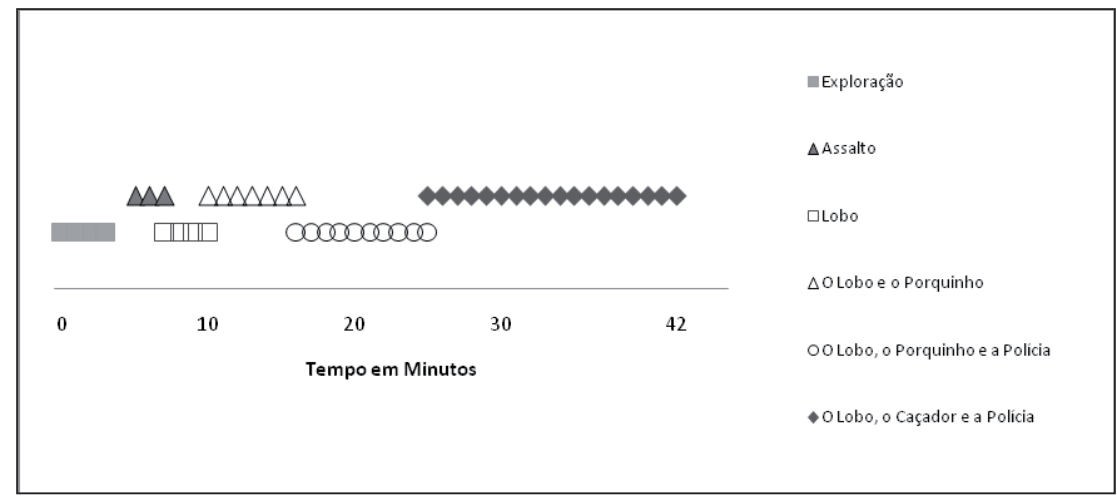

Figura 1- Sequência e duração dos temas das brincadeiras

Fonte: Ruiz, LC Batista, CG, O brincar em grupos de crianças com alteraçôes visuais.

\section{DESCRIÇÃo BREVE dA SESSÃO, RELATIVA AOS DIFERENTES TEMAS.}

Exploração: As crianças estão sentadas sobre um tapete de EVA. C vai até os brinquedos primeiro. $\mathrm{P}$ descreve os brinquedos que estão disponíveis. $\mathrm{C}$ pega um boneco de pano e observa. G encontra os blocos de madeira e começa e empilhá-los. C pega o "Lego" e começa a encaixá-los. 
$\mathrm{O}$ assalto: brincadeira individual: $\mathrm{G}$ empilha os blocos de madeira ("Pequeno Engenheiro") dizendo ser um muro. G dialoga com $\mathrm{P}$ enquanto $\mathrm{C}$ brinca também com peças de encaixe em plástico ("Lego gigante"). G se mantém na atividade de construir e derrubar o muro, e diz que alguém quer assaltar o muro.

O lobo: C pega a "Casa das Chaves" e um boneco que diz ser o lobo. C começa a brincadeira, movimentando o boneco no papel de lobo fazendo uma voz grossa. Aproxima o lobo da casa e sopra a casa, dizendo que vai derrubá-la. G chama por $\mathrm{C}$ e pede que mande o lobo embora. Iniciam um diálogo sobre o lobo, organizando um enredo que lembra a história dos "Três Porquinhos".

O lobo e o porquinho: $\mathrm{C}$ sugere que $\mathrm{G}$ chame o porquinho. $\mathrm{G}$ chama e $\mathrm{C}$ pega outro boneco para representar o porquinho. $\mathrm{G}$ segue dialogando com $\mathrm{C}$ sobre a forma como o porco vai espantar o lobo. C simula brigas entre o porco e o lobo.

O lobo, o porquinho e a polícia: G segue dramatizando, chamando a polícia para prender o lobo. C manipula um boneco de pano, no papel da polícia, brigando e tentando pegar o lobo e o porquinho.

O lobo, caçador e a polícia: C pega um boneco e diz que é o caçador que vai matar o lobo. No enredo de C, o boneco que representa a polícia prende o boneco que representa o caçador, que também é preso pela polícia por matar o lobo (na casa de plástico representando a prisão).

\author{
Episódio 1: O caçador e a polícia \\ (incluído no tema - O lobo e o porquinho) \\ Contexto: G e C estấo sentados num tapete de borracha. G dialoga com C sobre uma maneira \\ de se livrar do lobo. C manipula o boneco, fazendo som de "urros" do lobo e G mostra-se as- \\ sustado com a brincadeira que elaboram. \\ C: Espera! Sabe quem você pode chamar? \\ G: Quem? Silêncio por alguns segundos. O caçador! Grita entusiasmado. \\ C: Não, o caçador não tem... \\ G: Quem eu posso chamar? Hein? A polícia pode prender o lobo! \\ C: Não.... \\ Faz-se silêncio por alguns segundos. \\ G: Por... \\ P: Quem, Carlos? Quem que vai chamar? \\ $\mathrm{G}$ : Chamar quem? \\ C: Ninguém. \\ G: E agora o lobo vai derrubar a minha casa. O que que eu faço? Diz mexendo os dedos dos pés, \\ mostrando tensão. \\ C: Você chama o porquinho que fica nessa casa. Aponta e póe a mão na casa de plástico. \\ G: Ah tá! Então eu vou construir outra. Se o lobo vier eu chamo logo o porquinho. \\ $\mathrm{C}$ : esconde dois bonecos de pano atrás do corpo. \\ C: Vai vim dois lobos. Olha para G e sorri, preparando a chegada dos lobos escondidos atrás de \\ seu corpo. \\ [...] C diz que os lobos náo aparecerão mais e abruptamente tira os bonecos de trás do corpo, \\ fazendo som de urro. $\mathrm{G}$ continua empilhando os blocos de madeira. \\ C: URRRRRRR. Faz som do lobo bravo. \\ G: Se assusta e derruba os blocos que estava empilhando. \\ G: Eu já derrubei minha casa! Ele nem deu tempo de derrubar. Eagora? O que que eu faço Carlos?
}




\section{ANÁLISE do EPISÓdIo}

\section{INTERAÇÁO CRIANÇA-CRIANÇA}

$\mathrm{C}$ e $\mathrm{G}$ seguem construindo uma brincadeira conjunta de acordo com a categoria Atividade Conjunta (1 a 19), em que G sustenta a brincadeira dialogando com C, e C faz maior uso dos brinquedos para representar os personagens da cena.

\section{INTERAÇÁO ADULTO-CRIANÇA}

P (8) faz uma intervenção no momento em que o enredo parece decrescer. Faz-se silêncio já que $C$ não responde aos questionamentos de $G$, nem aceita suas sugestóes para se livrar do lobo. P, que até então observava a brincadeira organizada por C e G, faz Comentáriol Pergunta (8) incentivando $\mathrm{C}$ a responder e dar continuidade à brincadeira.

\section{COMENTÁRIOS SOBRE O EPISÓDIO}

$\mathrm{G}$ faz algumas sugestôes para afastar o lobo, dizendo que poderiam chamar a polícia ou o caçador. C não aceita as sugestôes de $\mathrm{G}$, e propóem alternativas. $\mathrm{G}$ segue as sugestóes de $\mathrm{C}$.

$\mathrm{C}$ movimenta o boneco, simulando uma luta. G fica parado e faz perguntas sobre o que está acontecendo. C não responde. Em momentos de movimentação como nesse caso, em que o parceiro não verbaliza o que está acontecendo, a criança cega perde algumas informações, o que pode ser um empecilho para a continuidade da brincadeira.

Nesse momento a pesquisadora interfere, fazendo perguntas para que $\mathrm{C}$ faça mais descriçóes sobre o que ocorreu na açáo com as personagens. É importante que o adulto dê algumas orientações e faça algumas interferências para que a criança que faz uso da visão compreenda os meios que facilitam a compreensão da criança cega. Quando a pesquisadora interfere com perguntas que esclarecem o que está havendo, mostra também para G como ele pode formular essas perguntas. Em situaçôes semelhantes em outros episódios, P estimula $G$ a fazer perguntas, a pedir mais informaçóes sobre o que está acontecendo, de forma a ter mais autonomia na brincadeira. Dessa forma auxilia a continuidade da brincadeira conjunta e a interação entre as crianças.

\footnotetext{
Episódio 2: Chamando a polícia (incluído no tema - O lobo e o porquinho e a polícia)

Contexto: G segue tentando se livrar do lobo e chamar ajuda. Pede ajuda a P para dar sugestóes de quem pode chamar para pegar o lobo. C olha o boneco próximo dos olhos.

G: E agora? O que que en vou fazer?

G: Tia vem dar uma ajuda, por favor?

P: O que que eu faço?

G: Chama a policia.

P: Tem um telefone aqui...

G pega o telefone: A eu vou ligar para a polícia. Cadê a polícia? (faz movimento com os dedos, como se digitasse os números) Pan, pan, pan, pan, pan, pan. Alô, quem fala? Ah, é a polícia? Tudo bem. Ah... vem prender esse lobo? Tá bom.

$\mathrm{G}$ desliga o telefone e muda o tom de voz

G: Já to indo! Pum. (faz movimento com a mão como se estivesse batendo em alguém)

C olha para $\mathrm{G}$ e ri.

P: Tem um boneco aqui se você quiser que seja a polícia.
} 
G pega o boneco de pano sugerido por P.

$\mathrm{C}$ bate na construçáo de $\mathrm{G}$ com seu boneco de pano.

G: Não. Pára... (muda o tom de voz) Já prendi o lobo.

[...] G segue dialogando e dizendo que vai ligar para a polícia novamente, enquanto $\mathrm{C}$ movimenta os bonecos, fazendo som de urro.

\section{ANÁLISE DE EPISÓdIO}

INTERAÇÃO CRIANÇA-CRIANÇA

C e G seguem em Atividade Conjunta (1 a 14). C movimenta os bonecos e bate na construção de G. G usa um telefone em miniatura para ligar para a polícia.

\section{Interação adulto-criança}

P faz um Comentário/Pergunta (3), procurando a resposta de G sobre a maneira como poderia ajudá-lo. P segue fazendo Sugestão para uso de objeto $(5,9)$ para que $\mathrm{G}$ use os brinquedos que estão disponíveis para apoiar o diálogo com C.

\section{COMENTÁRIOS SOBRE O EPISÓDIO}

$\mathrm{G}$ inicia o episódio pedindo ajuda à $\mathrm{P}$ que procura estimular $\mathrm{G}$ a buscar soluçóes para a dificuldade que encontra na cena criada. Estimula sua participação e faz perguntas de modo a estimular $\mathrm{G}$ a pensar, evitando dar as repostas prontas. Oferece um objeto para facilitar a participação de $\mathrm{G}$ no enredo e a interação com $\mathrm{C}$ na brincadeira. $C$ não atende à ideia de $\mathrm{G}$ de prender o lobo, já que o boneco que representa o lobo continua em sua mão. G faz sons e diz que prendeu o lobo apenas de forma verbal, o que dificulta a compreensão de C sobre a prisão do lobo. P procura estimular $\mathrm{G}$ a utilizar mais os brinquedos, de forma que compreenda como a brincadeira se organiza e melhore sua interação com $\mathrm{C}$.

Episódio 3: Chamando a polícia mais uma vez

(incluído no tema - O lobo e o porquinho e a polícia)

Contexto: $\mathrm{G}$ segue ligando para a polícia e $\mathrm{C}$ não atende seu pedido de prender o lobo.

$\mathrm{G}:$ Ah, tá bom, eu chamo a polícia, ela que prende.

$\mathrm{P}:$ Ah...que tal?

$\mathrm{G}$ : Ah, tá. Eu vou chamar a polícia ela que prende. Ai ela vai prender o lobo e viveram felizes para sempre na sua casinha. ( $\mathrm{G}$ bate palmas em sinal de comemoração). E o lobo nunca mais veio. ( $\mathrm{G}$ faz um ritmo com a mão e canta, quando pára o ritmo pergunta). Cadê a polícia?

C observa um boneco de pano e o coloca dentro da Casa das Chaves.

G: Cadê o telefone? G procura o telefone. Encontra próximo de sua perna. Pi, Pi, Pi, Pi...Polícia? Vem aqui prender esse lobo?Políciaaa?Vem aqui prender! Vem! (G muda o tom de voz, para uma voz mais grave) Tồ indo, to indo!

P: Cadê a polícia?

G faz movimento batendo uma mão na outra. Prendi esse lobo.

P: Cadê o lobo?

G: Cadê o lobo?

C: Tá dentro da casa.

G: Cadê?

P: Mostra a casa pro Gui, Carlos!

G: Não, mostra a casa pra polícia, pra ela prender já.

P: Cadê a polícia?

G: Tá aqui. Ela já chegou.

P pega a mão de G e diz: Então, a casa é aqui ó... 
P leva a mão de $\mathrm{G}$ até a casa.

G: Mostra pra Polícia. Eu prendo, prendo. (G coloca a mão no boneco que C diz ser o lobo).

Prendi já.

C: Errei...

G: Prendi, prendi, Carlos!Prende esse lobo! Prende, prende!

C: Fecha a porta da casinha. Prendi na cadeia! E coloca o boneco dentro da casa.

\section{ANÁlISE DO EPISÓDIO}

\section{INTERAÇÃO CRIANÇA-CRIANÇA}

C e G continuam em Atividade Conjunta (1 a 21). G procura uma maneira de prender o lobo e neste episódio $\mathrm{G}$ consegue prender o lobo, pedindo para que $\mathrm{C}$ faça isso, já que até este momento $\mathrm{C}$ não acata a maneira de $\mathrm{G}$ prender o lobo, sem retirar o boneco de sua mão.

\section{INTERAÇÃO ADULTO-CRIANÇA}

P faz uma Avaliação Positiva da fala de G (2). P faz Comentários $(6,8,14)$ incentivando $\mathrm{G}$ a usar os bonecos para representar os personagens. Depois faz uma Sugestão para uso $e$ Localização do objeto $(12,16)$ e mostra para $\mathrm{G}$ a casa que C está usando para representar a cadeia, levando sua mão para explorá-la (17).

\section{COMENTÁRIOS SOBRE o EPISÓdIo}

$\mathrm{G}$ insiste pela prisão do lobo e busca formas para que isso aconteça. P faz perguntas para $\mathrm{C}$ de forma a buscar explicaçóes sobre o que está acontecendo e manter a atenção de $\mathrm{G}$ na brincadeira. G mostra atenção após a resposta de C. C participa da brincadeira manipulando os brinquedos, enquanto $G$ manuseia pouco o brinquedo e neste episódio encontra uma alternativa para que o lobo seja preso: pede que $\mathrm{C}$ coloque o lobo na prisão. $\mathrm{C}$ atende ao pedido de $\mathrm{G}$ e o problema da prisão do lobo é resolvido.

\section{Discussáo}

A partir da análise dos episódios e do exame da transcrição da sessão completa, observou-se que os participantes, nessa sessáo, criaram enredos elaborados e com crescente colaboração entre si. C busca os brinquedos primeiro e G precisa da descrição de P sobre quais brinquedos estão disponibilizados e sua localização para iniciar a brincadeira. A descrição do adulto nesse momento é importante para o engajamento de $G$ no brincar. Inicialmente $\mathrm{G}$ manipulou pouco os brinquedos e fez perguntas procurando entender algumas açóes que não foram verbalizadas por $\mathrm{C}$. Alguns questionamentos de $\mathrm{P}$ também contribuíram para essa compreensão. Silveira, Loguercio e Sperb (2000) destacaram em estudos com crianças cegas que o brincar simbólico ocorreu de forma mais elaborada a partir da intervenção do adulto, que inicialmente fazia as propostas para a brincadeira de faz de conta. Observou-se que a pesquisadora, no presente estudo, fez perguntas e intervençôes, porém a interação ocorreu de forma articulada entre os próprios participantes. Observou-se que $\mathrm{G}$ e $\mathrm{C}$ criaram um enredo conjunto com a colaboração ora de um, ora do outro, com pouca interferência do adulto nessa elaboração. A ideia inicial para a organização do enredo partiu das crianças. A intervenção de 
P foi centrada nas formas para que $G$ compreendesse as açóes não verbalizadas por $C$ e no incentivo a maneiras de brincar que favorecesse o brincar conjunto.

Conforme descrito anteriormente, Preisler (1997) destacou algumas dificuldades na relação entre crianças cegas e videntes. No presente estudo, em alguns momentos das brincadeiras no grupo, $C$ mostrou brinquedos para $G$, procurando a atenção visual de $G$ ou realizou açóes sem verbalizar o que estava acontecendo. $G$ fez perguntas que inicialmente não foram respondidas por C. Nesse momento P reforçou as perguntas de G ou fez outras, buscando a continuidade da interação de $\mathrm{G}$ com o parceiro. É importante destacar que, com o decorrer das sessóes, $\mathrm{G}$ utilizou mais o diálogo, intensificou as perguntas, se movimentou mais e buscou brinquedos para participar das brincadeiras.

Foi possível observar que $\mathrm{G}$ fez uso da linguagem como forma de buscar informaçóes sobre o ambiente, sobre o enredo e para compreender as açóes de C. Durante a composição do enredo, $\mathrm{G}$ fez perguntas para compreender as açóes de $\mathrm{C}$ com os brinquedos (EP 1, EP 2), quando estas não eram verbalizadas. É um recurso que possivelmente tenha aprendido no relacionamento cotidiano para melhor compreender o que acontecia à sua volta. É importante destacar que, segundo a mãe, a família recebeu orientaçóes relativas à deficiência visual, desde os primeiros meses de vida de G. De forma geral, as pessoas não descrevem suas açóes, o que dificulta a compreensão do que está ocorrendo para as pessoas cegas. Essa descrição pode surgir como resposta ao pedido da pessoa cega, e pode gerar um hábito de descrição de açóes, nos parceiros mais constantes. Vygotsky (1997) destaca que a pessoa cega recebe informaçóes por meio dos sentidos remanescentes, e as organiza por meio da linguagem. Por isso, a iniciativa de $G$ de perguntar se torna relevante para sua autonomia na busca de informaçóes. Deve-se destacar, também, a importância do conhecimento das pessoas que convivem com a criança cega sobre a descrição de situaçóes e açóes. Nesse sentido, Nunes e Lomônaco (2010) discutem que o indivíduo cego vai precisar de um ambiente diferenciado e adaptado, que propicie a satisfação de suas necessidades. Nesses momentos, a forma de apresentar a informação constitui-se em um recurso importante e diferenciado para melhorar o entendimento de G sobre as açóes de C.

No desenvolvimento das sessóes, foi possível ainda perceber momentos em que G liderou a brincadeira, utilizando a linguagem como meio para participar. Batista e Laplane (2007) abordam questóes relacionadas ao isolamento social e o quanto a criança com deficiência visual tem dificuldades em experimentar papéis valorizados socialmente, como o da liderança. Notou-se o entusiasmo de $\mathrm{G}$ em várias situaçóes em que suas solicitaçóes foram atendidas, na exposição de novas ideias para o enredo e na representação de papéis relativos à cena elaborada.

Na participação de C, observou-se a elaboração de enredos e a busca pela integração com $\mathrm{G}$ de forma crescente. Inicialmente, $\mathrm{C}$ atuava de forma menos colaborativa, desmontando as construçóes de $\mathrm{G}$, aceitando poucas ideias de G e P. A análise dos registros das sessões subsequentes mostrou que passou a aceitar com mais frequência as sugestóes de $G$, a responder às intervençóes e às sugestóes de interação de $\mathrm{P}$ e a participar na construção conjunta dos enredos. Inclusive, foram registrados exemplos de sessóes em que buscou brinquedos, com a intenção de continuar o enredo de sessôes anteriores. Observou-se, também, crescente coerência nos enredos elaborados. No episódio (EP1) em que C assustou G com a chegada abrupta dos lobos, elaborou uma situação para ludibriar o parceiro. Mesmo não sendo uma 
elaboração que favoreça a continuidade da brincadeira, destaca-se a habilidade de $\mathrm{C}$ para tal elaboração e a possibilidade de direcionar esta habilidade para situaçóes mais colaborativas. De forma geral, foram observadas mudanças nas formas de brincadeira de $\mathrm{G}$ e $\mathrm{C}$, o que é relevante, conforme destacado, entre outros autores, por Vygotsky (1998), quando destaca o brinquedo como uma atividade condutora do desenvolvimento da criança.

É relevante, também, discutir o papel da pesquisadora nessas interaçóes. $\mathrm{P}$, durante a sessão, descreveu os brinquedos e sua localização para que $\mathrm{G}$ iniciasse a brincadeira, orientou C quanto a alguns comportamentos facilitadores na interação, esteve atenta às formas de organização da brincadeira em grupo (categoria Comentários), e, de forma geral, procurou encorajar a interação entre os participantes. Nesses momentos, orientou as crianças, buscando formas de compreensão de aspectos menos identificáveis da elaboração do enredo ou da interação. A intervenção de $\mathrm{P}$, observada nos momentos de dificuldade de entendimento das açóes de $\mathrm{G}$ sobre o enredo ou as açóes de $\mathrm{C}$, pautou-se, centralmente, por induzir $\mathrm{C}$ a descrever suas açóes, ao invés de fazer essas descrições. Outra ação importante de P foi a escolha dos brinquedos com atenção às características que poderiam facilitar a manipulação e o interesse dos participantes, considerando as especificidades em decorrência da deficiência visual. Embora não tenha havido adaptação de brinquedos e tenha-se utilizado brinquedos encontrados no comércio comum, houve o cuidado com as cores contrastantes, o tamanho das miniaturas, a presença de brinquedos sonoros e a disponibilização de materiais que permitissem a elaboração do brincar simbólico. A descrição inicial dos brinquedos disponibilizados na sala auxiliou $G$ a escolher e a se dirigir ao que lhe despertou interesse. No decorrer das sessóes subseqüentes, foi possível observar em $\mathrm{G}$, maior movimentação e manipulação dos brinquedos e, em $\mathrm{C}$, mais exemplos de permissão para que $\mathrm{G}$ tocasse nos brinquedos que estava utilizando, possivelmente como decorrência da atuação de P.

Observou-se, ao longo das sessões, uma evolução no que diz respeito à interação entre os participantes, com maior alternância no papel de liderança, crescente colaboração entre os parceiros e maior duração dos enredos propostos a partir da contribuição entre eles. A criança com deficiência visual mostrou condiçóes de brincar como qualquer criança, uma vez oferecidas condiçóes de interagir com parceiros. Aprenderá a brincar se tiver parceiros para brincar com ela, que compreendam que sua forma de interagir pode ser diferente. E ser diferente não quer dizer que seja inferior.

\section{Conclusóes}

A partir dos dados observados, conclui-se que o grupo de brincadeiras pode ser considerado um ambiente que favorece a interação entre crianças com deficiência visual e que constitui uma situação dinâmica, na qual as formas de participação da criança podem mudar, de modo que obstáculos sejam superados.

O papel do adulto é central, na escolha e disposição de materiais, na descrição inicial dos brinquedos disponibilizados, no favorecimento da participação da criança com deficiência visual, no respeito às iniciativas das crianças e na intervenção em caso de disputas.

A participação da criança no grupo de brincadeira, de forma ativa, com a intermediação do adulto, contribui para sua formação global, com destaque para a autonomia e autoconfiança. 
Os dados do estudo são relevantes para o planejamento de atividades no contexto da educação inclusiva, uma vez que salientam capacidades das crianças com deficiência visual e formas para superar dificuldades na interação, a partir da intervenção do adulto no planejamento da situação de brincadeira e no acompanhamento da mesma.

\section{REFERÊNCIAS}

BATISTA C.G.;LAPLANE A.L.F. Modalidades de atendimento especializado: o grupo de convivência de crianças com deficiência visual. In: MASINI, E.F.S. (Org.). A pessoa com deficiência visual: Um livro para educadores. São Paulo: Vetor; 2007. p. 383-391

BOMTEMPO, E. Brincar, Fantasiar, criar e aprender. In: OLIVEIRA, V. B. (Org.). O brincar e a criança do nascimento aos seis anos. 3 ed. Petrópolis: Vozes, 2000. p.127-149.

CARVALHO, A.M.A;PEDROSA, M.I. Cultura no grupo de brinquedo. Estudos de Psicologia, Natal, v.7, n.1, p.181-188, 2002.

GÓES, M.C.R. A abordagem microgenética na matriz histórico-cultural: uma perspectiva para o estudo da constituição da subjetividade. Cadernos Cedes, Campinas, v.50, n.50, p.9-25, 2000.

HUEARA L. et al. O faz de conta em crianças com deficiência visual: identificando habilidades. Revista Brasileira de Educação Especial, Marília, v.12, n.3, p.351-368, 2006.

HUIZINGA, J. Homo Ludens: o jogo como elemento da cultura. Trad. J.P. Monteiro. 5. ed. São Paulo: Perspectiva/EDUSP, 2008.

KISHIMOTO, T. M. O jogo e a educação infantil. São Paulo: Pioneira, 1994.

MASINI, E.F.S. (Org.). A pessoa com Deficiência Visual, um livro para educadores. 1 ed.,São Paulo:Vetor, 2007.

NUNES, S.; LOMÔNACO, J. F. B. O aluno cego: Preconceitos e Potencialidades. Revista Semestral da Associação Brasileira de Psicologia Escolar e Educacional. São Paulo, v.14, n.1, p.55-64, 2010.

OLIVEIRA, V.B; BOMTEMPO, E. O processo lúdico e a formação da identidade social e cultural. In: AMIRALIAN, M.L.T.M., (Org.). Deficiência Visual: perspectivas na contemporaneidade. São Paulo: Vetor, 2009. p.117-129

PREISLER, G. Social and Emotional development of blind children: A longitudinal study. In: LEWIS, V.; COLLIS, G.M (orgs.). Blindness and Psychological development in young children. London: England; The British Psychological Society, 1997. p.116-129.

SILVEIRA A., LOGUERCIO L., SPERB T. A brincadeira simbólica de crianças deficientes visuais pré-escolares. Revista Brasileira de Educação Especial. Marília, v.6, n.1, p.133-146, 2000.

VYGOTSKY, L.S. A formação social da mente. COLE, M. et al. (Org.), 6 ed. São Paulo: Martins Fontes, 1998.

.Obras escogidas: fundamentos de defectologia. BLANK, J.G. Trad. Madri: Visor; 1997.

WARREN, D.H. Blindness and Children:An Individual Differences Approach. Cambridge: Cambridge University Press, 1994.

Recebido em: 08/07/2013

Reformulado em: 06/02/2014

Aprovado em: 07/04/2014 